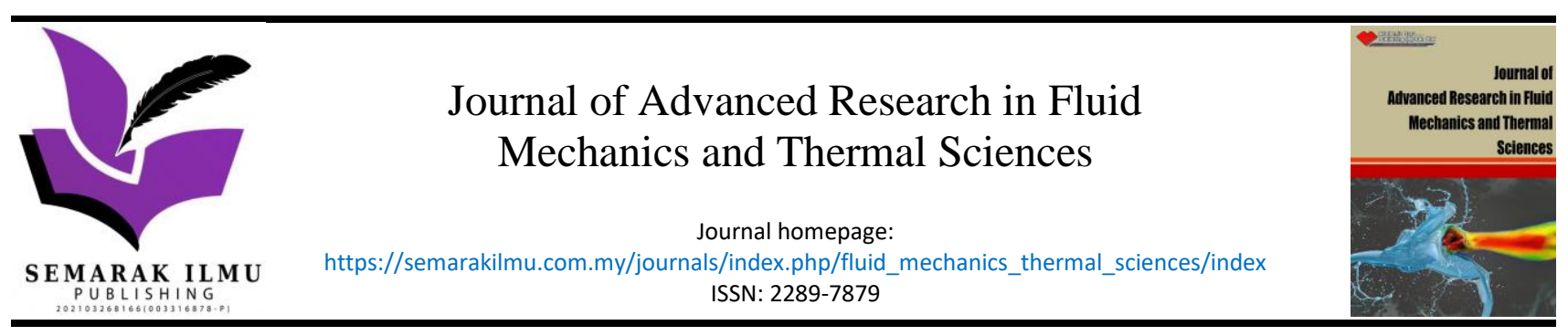

\title{
Investigation of Non-Newtonian Fluid Behavior and Coefficient of Friction in Water Hammer Phenomena
}

\author{
Nawal Achak ${ }^{1, *}$, Ouafae Rkibi ${ }^{1}$, Bennasser Bahrar ${ }^{2}$, Kamal Gueraoui ${ }^{1}$ \\ Energy Research Center, Faculty of Sciences, Mohammed V University, Rabat, Morocco \\ 2 Condensed Matter Physics Laboratory, FST Mohammedia, Hassan II University Casablanca, Morocco
}

\section{ARTICLE INFO ABSTRACT}

\section{Article history:}

Received 14 August 2021

Received in revised form 20 October 2021

Accepted 25 October 2021

Available online 27 November 2021

\section{Keywords:}

Non-Newtonian fluid; Unstable flow; Water hammer phenomenon

\begin{abstract}
An unstable flow of non-Newtonian fluid, with friction in a pipe is studied, describing the water hammer phenomenon. The equations of the problem are given, then solved by a numerical approach. The non-Newtonian behavior of the fluid, as well as the effect of the coefficient of friction which represents an additional mechanism of energy dissipation are investigated. The 1D and 2D problem is used simultaneously, based on the Runge-kutta method for the descritization in time, Finite differences, Characteristics for the descritization in space. The results of this article show by verifying with experience that these methods used, in addition to being simple, are also effective and give reasonable results.
\end{abstract}

\section{Introduction}

The water hammer phenomenon means a pressure surge or shock wave that can oscillate in a pipe system with a speed close to that of sound in water. This gradual pressure wave in the system can cause an explosion or pipeline implosion. The distribution and amplitude of the pressure wave front depend on the roughness of the pipeline, blockages due to sediment deposition, corrosion, etc. [1]. Recorded pressures are a tool for estimating driving conditions after studying pressure damping models. This methodology, based on studies of transient flows, has recently attracted the attention of several researchers [2-7]. Establishing an understanding of the damping mechanisms of water hammer waves is fundamental to the development of the transient study, and the design of pipeline safety accordingly. The friction on the wall makes it possible to study the damping of water hammer waves which reveals the importance of the present study. This translates into adding the term of friction to the equations governing the problem, and represents a means of predicting the damping of the amplitude of the pressure waves face to models of frictionless water hammers.

The simplest known friction model is the quasi-stable model [8-11]. Indeed, the decrease in the pressure amplitude observed by this model was found to be slower than that obtained in the experiments $[12,13]$.

\footnotetext{
* Corresponding author.

E-mail address: achaknawal3@gmail.com
}

https://doi.org/10.37934/arfmts.89.1.175184 
Pezzinga [14] proved that the unsteady coefficient of friction depends on the properties of the system, location and time, by making comparisons with numerical results based on a quasi-twodimensional (2D) model. Pezzinga [15] and Brunone et al., [16] gave an example in which an increase in the unsteady friction coefficient of $35 \%$ has little effect on the pressure time histories at the valve. unstable frictional stresses were greater in pipe systems compared to a single straight pipe and also had a smaller effect on pressure wave damping [17]. With the increase in the product of the coefficient of a friction as well as the Reynolds number of the initial flow [17]. Wylie [12], Brunone et al., [18] and Soares et al., [19] have adopted trial and error procedures to have the unsteady coefficient, which gives the best fit. Adamkowski and Lewandowski [20] determined the difference between predicted and measured pressure time histories at the valve using the difference between the areas enveloped by the pressure histories and the center of the pressure oscillations. Nikpour et al., [21] and Duan et al., [22] used the differences between the predicted and measured peaks of the valve pressure time histories, to assess the validity of their numerical models. Prashanth Reddy et al., [23] used the normalized mean squared deviation in order to quantify the difference between the predicted and measured time histories of pressure and to specify the unsteady coefficient of friction.

Experimental studies by Holmboe and Rouleau [24], Brunone et al., [18] and Adamkowski and Lewandowski [20] show that the pressure waves are smoothed as they propagate in the pipe, and finally their amplitudes are attenuated. Indeed, the pressure waves predicted by quasi-stationery and acceleration-based models, for instance in the studies by Wylie [12], Brunone et al., [18], and Soares et al., [19], exhibit progressive wavefronts before damping, but the model of Pezzinga [25] describes a progressive change in the pressure wave. Whatever the model used (quasi-stationary, based on acceleration, quasi-2D or 3D-CFD), the presence of the term of friction does not change the hyperbolic nature of the problem. indeed, it was recognized by Szymkiewicz and Mitosek [26] in their studies on quasi-stable models based on acceleration. Again, friction in quasi-stationery and acceleration-based models has no influence on the wavefront, which remains sharp before damping. For this reason, the study added a diffusive term to refine the pressure wave front, for cases where the number of currents is less than unity. The present study introduces the effects of non-Newtonian bahavior fluid flow and the coefficient of friction that introduces an additional mechanism of energy dissipation. Also, the experimental verification explaining the actual water hammer phenomenon.

\section{Methodology}

\subsection{Governing Equations}

\subsubsection{Global system}

In the transient pipeline flow (Figure 1), the continuity and momentum global equations are given by the following system (Eq. (1)) [27]:

$$
\left\{\begin{array}{c}
\frac{\partial \mathrm{H}}{\partial \mathrm{t}}+\frac{a^{2}}{g} \frac{\partial \mathrm{V}}{\partial \mathrm{x}}=0 \\
\frac{\partial \mathrm{H}}{\partial \mathrm{x}}+\frac{\partial \mathrm{V}}{\partial \mathrm{x}}+\mathrm{J}_{\mathrm{q}}=0
\end{array}\right.
$$

where $V$ is average velocity, $\mathrm{H}$ is piezometric head, $a$ is wave speed, $\rho$ is density, $\mathrm{t}$ is time and $J_{q}$ is quasi-steady friction. 


\subsubsection{Local system}

In the transient pipeline flow, the continuity and momentum local equations are given by the following system (Eq. (2)) [28]:

$$
\left\{\begin{array}{c}
\frac{\partial H}{\partial t}+\frac{a^{2}}{g} \frac{\partial v}{\partial x}=0 \\
\frac{\partial v}{\partial t}+g \frac{\partial H}{\partial x}=\frac{1}{r \rho} \frac{\partial}{\partial r}\left(r \frac{\partial \tau}{\partial r}\right)
\end{array}\right.
$$

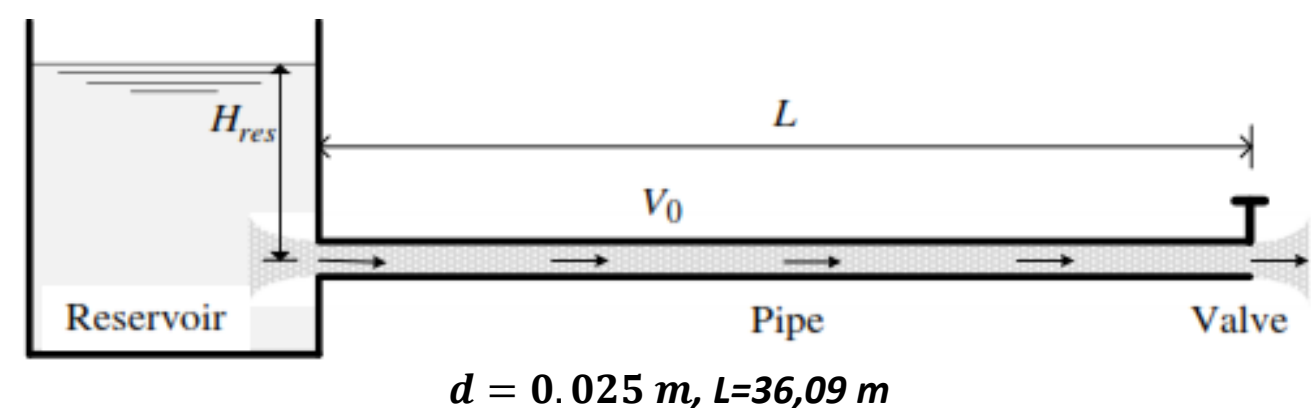

Fig. 1. Schematic of the reservoir-pipe-valve system [28]

\subsubsection{Initial conditions}

The initial conditions correspond to the steady state flow. So, these conditions can be written as:

$\frac{\partial \mathrm{v}}{\partial \mathrm{x}}=0$

$\frac{\partial P}{\partial x}=-\frac{2 \tau_{0}}{R}$

Where $\mathrm{R}$ is the inner radius of the pipe.

\subsubsection{Boundary conditions}

After the valve closure, the velocity is set to zero at the valve boundary. At the reservoir, a constant pressure head is associated. In contact, the flow boundaries with the pipe wall have zero velocity. Therefore, these boundary equations can be written as follows (Eq. (5) to Eq. (7)):

$\mathrm{v}_{(\mathrm{r}=\mathrm{R})}=0$

$\mathrm{v}_{(\text {valve })}=0$

$\mathrm{H}_{\text {reservoir }}=$ cte

where $\mathrm{R}$ is the inner radius of the pipe. 


\subsection{Non-Newtonian Behavior}

The equation which represents the shear stress of the fluid is (Eq. (8)) [27]:

$\tau=\mu \dot{\gamma}$

where $\mu$ and $\dot{\gamma}$ are apparent viscosity and shear rate respectively.

The power-law is given by the following equation, with the fewest possible parameters.

$\mu=m(\dot{\gamma})^{\mathrm{n}-1}$

where $m$ and $n$ are two empirical curve fitting parameters, also known as the fluid consistency coefficients and the flow behavior index respectively. If $n$ is fixed to one and $\mathrm{m}$ is set to $\mu_{0}$, the Newtonian fluid equation is obtained. This allows to investigate $\mathrm{n}$ values, in the power law model during transient fluid flows.

\subsection{Quasi-Steady Friction Model}

The quasi-steady friction model supposes that there is no contribution due to the unsteady flow (i.e., $J_{s}=0$ ) and that only the quasi-steady term of the pipe resistance contributes to the dampening due to friction, hence the name quasi-steady friction. This contribution to the friction term is computed using the formula

$J_{S}=\frac{f}{D} \cdot \frac{V|V|}{2 g}$

Which $V$ is average cross-sectional velocity, $f$ is Darcy Weisbah friction factor. In the laminar flow, the friction coefficient $f$ is concluded based on the Reynolds Number:

$f=\frac{64}{R_{e}}$

Where $R_{e}$ is Reynolds Number.

\subsection{Numerical Method}

The governing equations are solved using the finite difference and characteristics methods, and the system of equations over time, is solved using a fourth-order Runge-Kutta scheme.

The systems (Eq. (1) and Eq. (2)) are given in matrix form (Eq. (12))

$\frac{\partial\{\mathrm{W}\}}{\partial \mathrm{t}}=-[\mathrm{B}] \frac{\partial\{\mathrm{W}\}}{\partial \mathrm{z}}+\{\mathrm{c}\}$

with the unknown vector: $\{W\}=\{H \vee\}$

$\frac{\partial\{\mathrm{W}\}}{\partial \mathrm{t}}=\mathrm{f}(\mathrm{W}, \mathrm{t})$ 


$$
\{\mathrm{W}\}^{\mathrm{N}+1}=\{\mathrm{W}\}^{\mathrm{N}}+\frac{1}{6}\left[\left\{\mathrm{~K}_{1}\right\}+2\left\{\mathrm{~K}_{2}\right\}+2\left\{\mathrm{~K}_{3}\right\}+\left\{\mathrm{K}_{4}\right\}\right]
$$

\section{Results}

In the present study, the copper pipe has an internal diameter of $0.025 \mathrm{~m}$ and a length of 36,09 $\mathrm{m}$ with laminar flow conditions, the fluid used with high viscosity oils $\left(\mu=0.03484 \mathrm{~N} \cdot \mathrm{s} / \mathrm{m}^{2}\right)$. The test is initiated by a sudden closing of the valve, which creates the excision of the fluid flow to the valve, causing pressure and velocity oscillations, propagating along the pipe. The Newtonian and nonNewtonian velocity profile at the midpoint is represented (Figure 2 to Figure 5). Also, the representation of the pressure history at the midpoint and the valve is given (Figure 6), the history of average velocity at the midpoint and at the tank is also presented (Figure 7).

\subsection{Velocity Profile}

To better illustrate the variations in the transient velocity profile for a Newtonian and nonNewtonian fluid, the axial velocity in the radial direction at midpoint is calculated at several time sections, from the 2D simulation (the present study) (Figure 2, Figure 4 and Figure 5), and also compared with the experimental work (Figure 3) [26]. The coefficients of the power-law model are chosen to be equal to 0.6 . The initial viscosity of the power-law model is set to the viscosity of the corresponding Newtonian fluid, so for $n=1$, the characteristics of the Newtonian fluid is obtained.

In addition, the flow characteristics, which result from the nonlinear property of the fluid, can be identified (Figure 4 and Figure 5) by showing that the velocity distribution changes significantly due to the behavior of the non-Newtonian fluid. The velocity gradient increases in the flow section, and the increase in the velocity gradient in the vicinity of the pipe wall causes a drop in the viscosity value. Figure 2 illustrates that the consistency between the two results verifies the computer code implemented and the method used in this study.

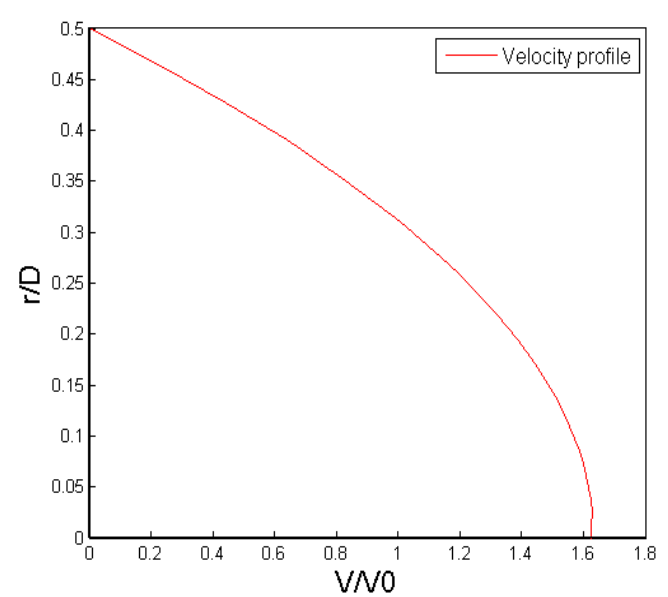

(a)

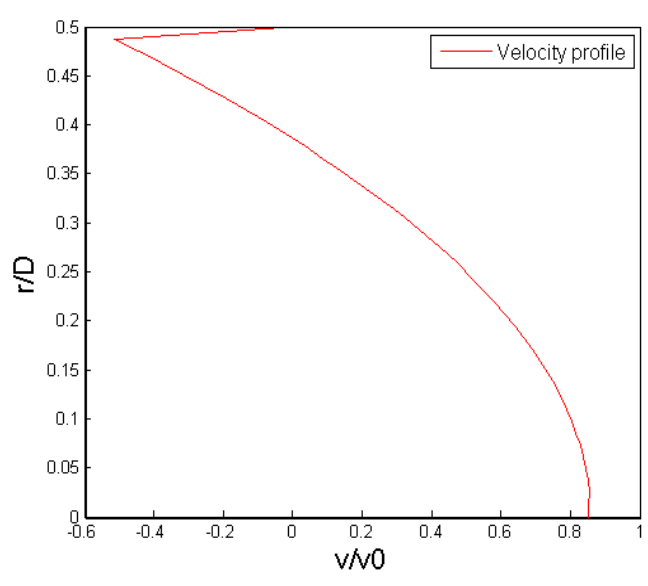

(b) 


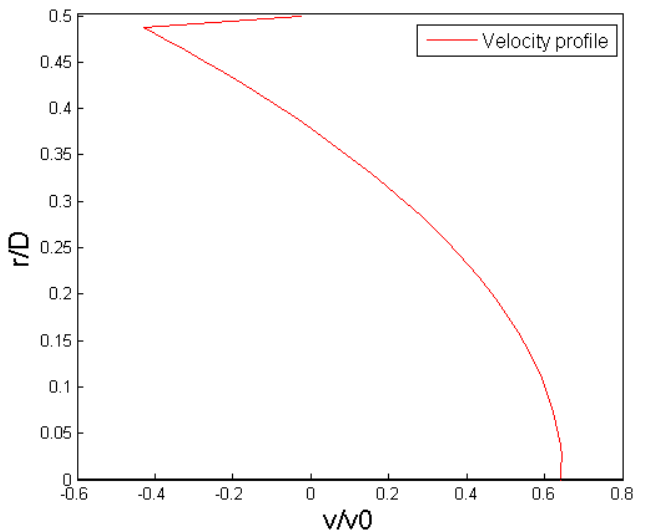

(c)

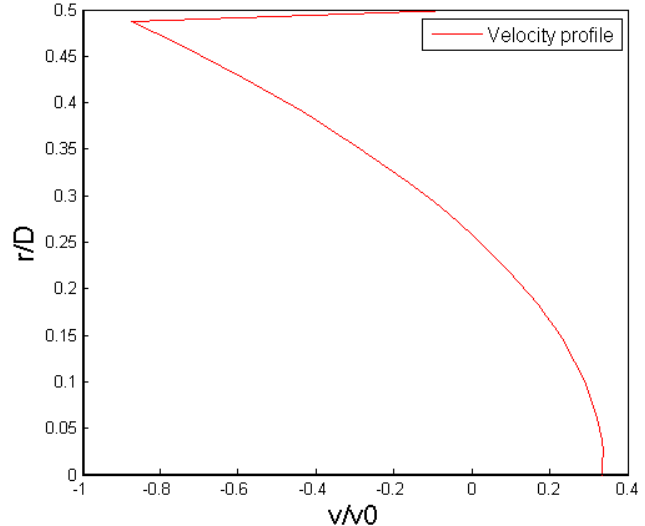

(d)

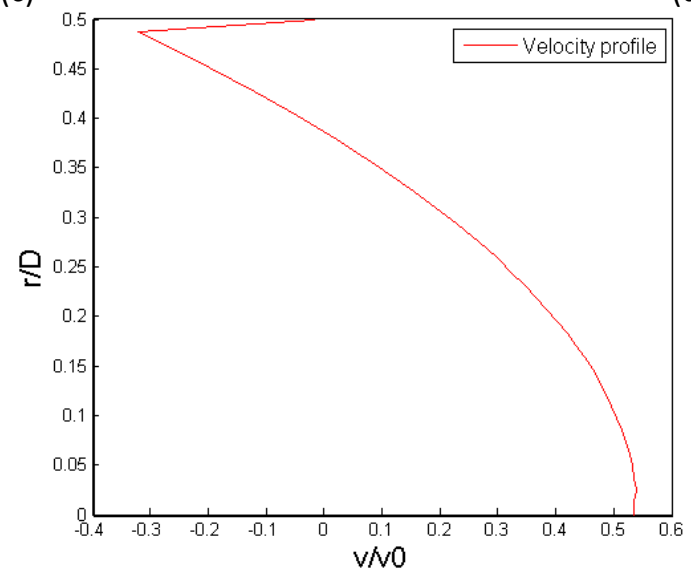

(e)

Fig. 2. Velocity profiles at the midpoint of pipe for Newtonian fluid $n=1: t=0, t=1 L / a$, $\mathrm{t}=2 \mathrm{~L} / \mathrm{a}, \mathrm{t}=3 \mathrm{~L} / \mathrm{a}, \mathrm{t}=4 \mathrm{~L} / \mathrm{a}$

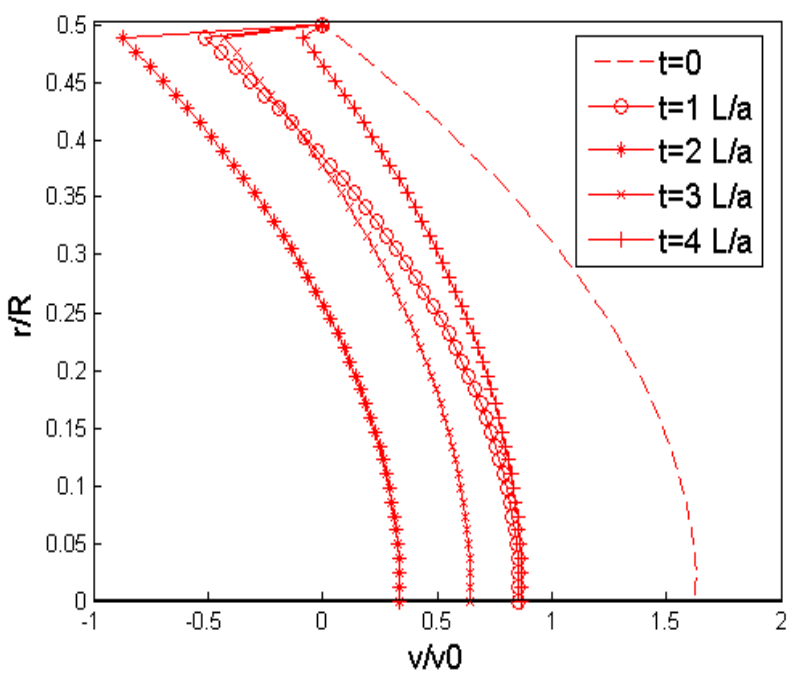

(a)

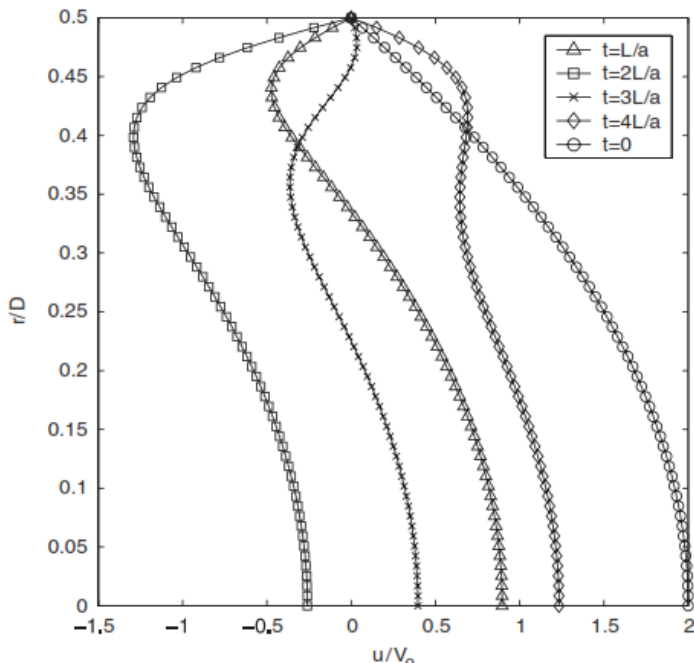

(b)

Fig. 3. Velocity profiles at midpoint of pipe for Newtonian fluid $n=1$ : (a) present study (b) study by Wahba [29] 


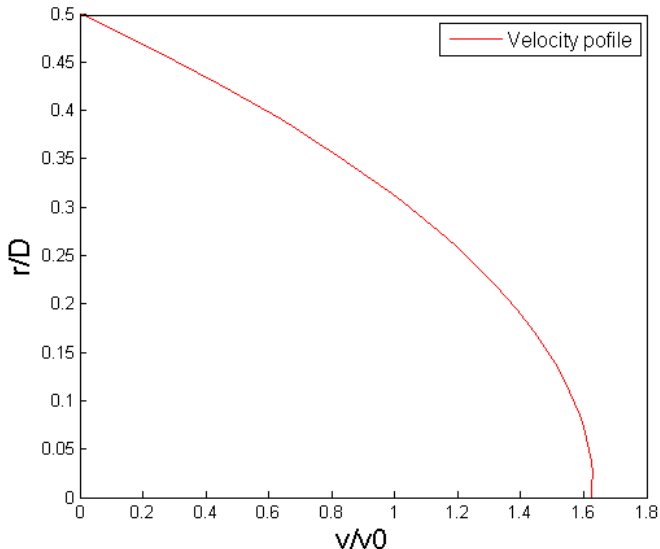

(a)

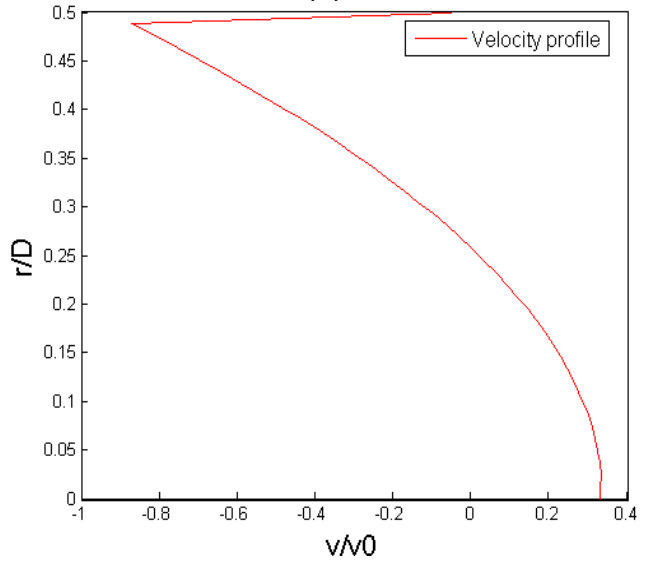

(c)

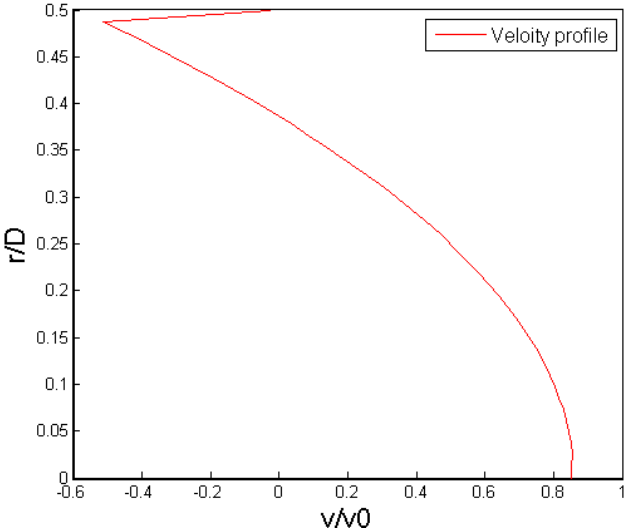

(b)

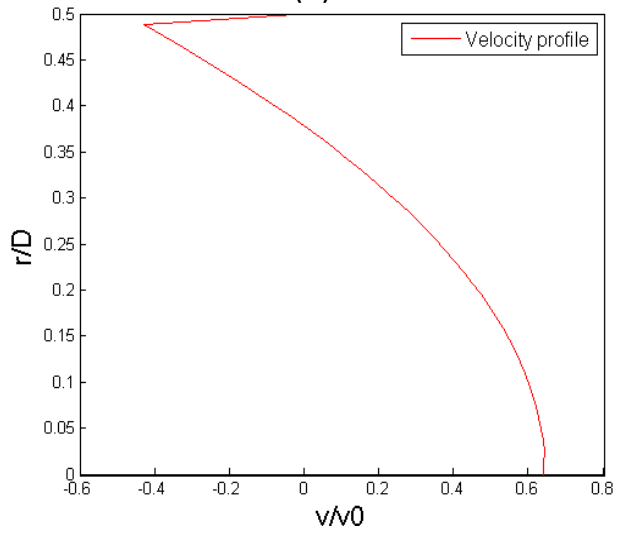

(d)

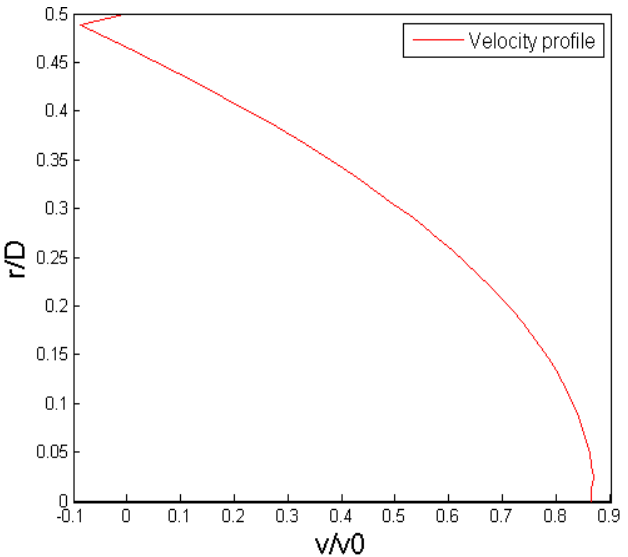

(e)

Fig. 4. Velocity profiles at the midpoint of pipe for non-Newtonian fluid $n=0,6: t=0, t=1$ $\mathrm{L} / \mathrm{a}, \mathrm{t}=2 \mathrm{~L} / \mathrm{a}, \mathrm{t}=3 \mathrm{~L} / \mathrm{a}, \mathrm{t}=4 \mathrm{~L} / \mathrm{a}$ 


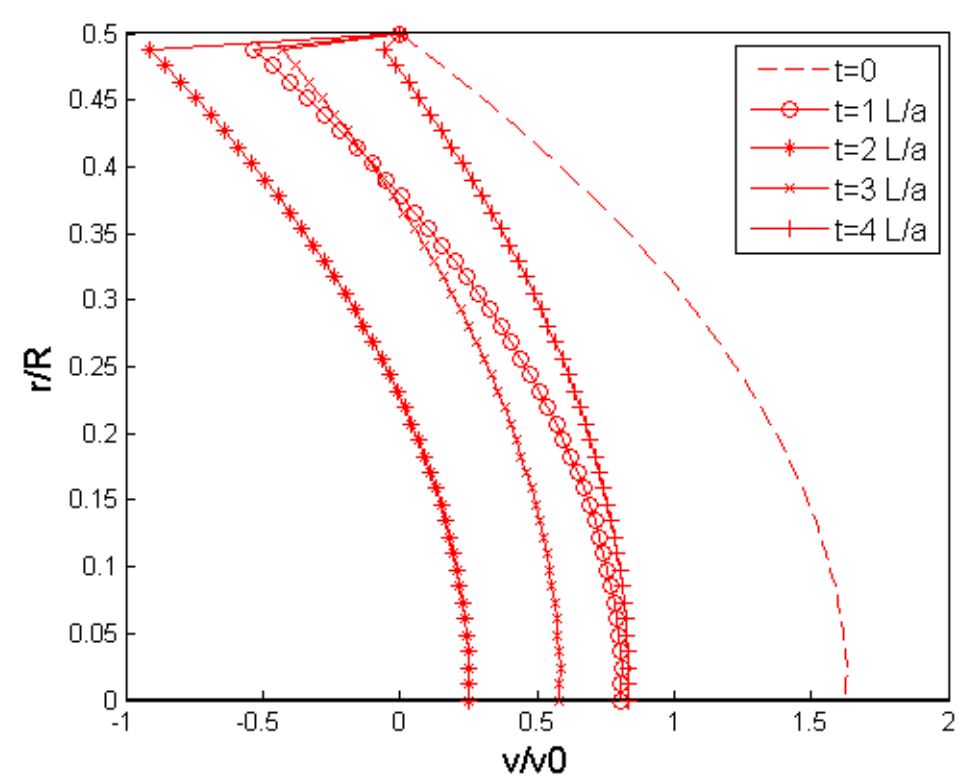

Fig. 5. Velocity profiles at the midpoint of pipe for nonNewtonian fluid $\mathrm{n}=0,6$ at several time sections

\subsection{Effect of the Friction Coefficient}

Figure 6 represents the peak pressure values and the shape of the pressure history at the valve and midpoint when using the classic boundary expression. While Figure 7 illustrates the average velocity history at tank, and midpoint. The higher value of the friction factor has a greater retardation effect on the reflection of the pressure wave, which is consistent with the literature, indeed more the value of friction coefficient increases the effect becomes more important, which is illustrated by the remarkable retardation on the value $f=0.5$ compared to $f=0.2$, and no effect for frictionless. Therefore, the coefficient of friction influences the damping of the pressure waves.

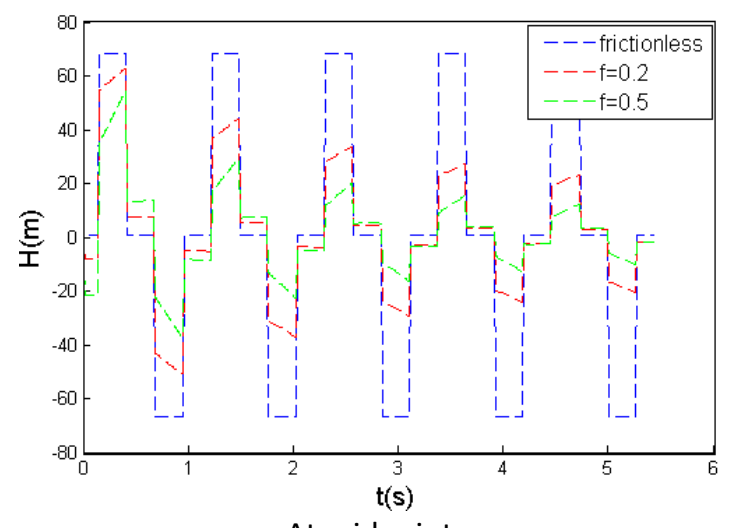

At midpoint

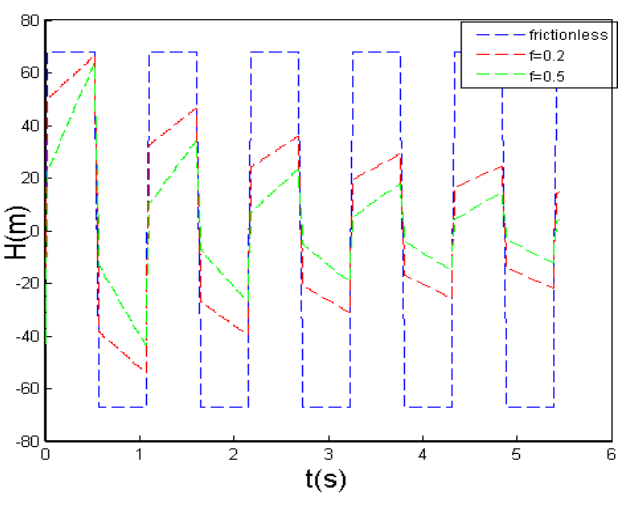

At valve

Fig. 6. Presser histories at the valve and the midpoint of pipe in frictionless and steady friction model 


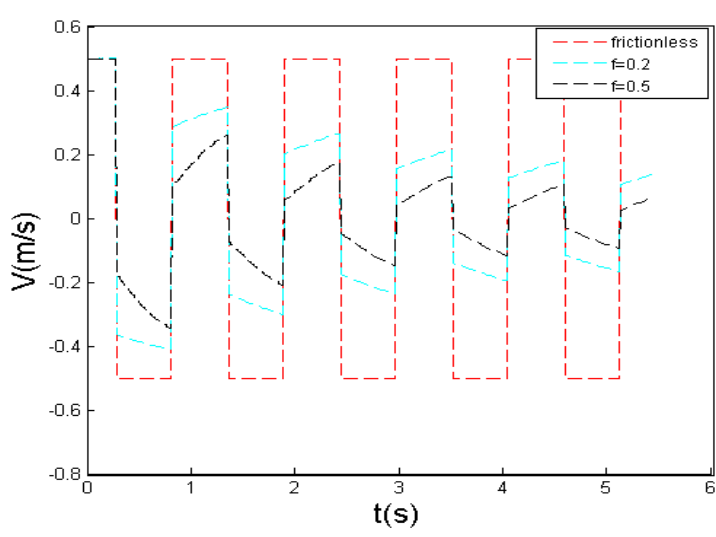

At reservoir

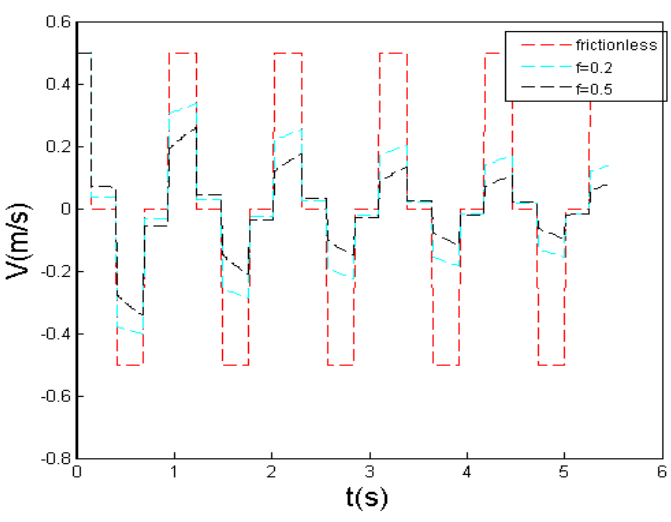

At midpoint

Fig. 7. Average velocity histories at the valve and the midpoint of pipe in frictionless and steady friction model

\section{Conclusions}

In the present study 2D methods are heavy in computation, so the $1 \mathrm{D}$ and 2D problem is used simultaneously and a numerical method based on Runge-kutta, characteristics and finite differences are proposed. The required cross-sectional velocity gradient of the transient power law was calculated based on that of the steady-state flow. Also, an approximation of average velocity and pressure history is shown. Therefore, the velocity distribution changes significantly due to the behavior of the non-Newtonian fluid, and friction coefficient. The higher value of the friction factor has a larger retardation effect on the reflection of pressure wave; therefore, the friction coefficient influences the damping of the pressure waves.

\section{References}

[1] Kandil, M., A. M. Kamal, and T. A. El-Sayed. "Effect of pipematerials on water hammer." International Journal of Pressure Vessels and Piping 179 (2020): 103996. https://doi.org/10.1016/j.ijpvp.2019.103996

[2] Fathi-Moghadam, Manoochehr, and Sajad Kiani. "Simulation of transient flow in viscoelastic pipe networks." Journal of Hydraulic Research (2019). https://doi.org/10.1080/00221686.2019.1581669

[3] Thete, Sumeet, Kaustubh Bhat, and M. R. Nandgaonkar. "2D Numerical Simulation of Fluid Flow over a Rectangular Prism." CFD Letters 1, no. 1 (2009): 43-49.

[4] Duan, H. F., P. J. Lee, T. C. Che, M. S. Ghidaoui, B. W. Karney, and A. A. Kolyshkin. "The influence of non-uniform blockages on transient wave behavior and blockage detection in pressurized water pipelines." Journal of HydroEnvironment Research 17 (2017): 1-7. https://doi.org/10.1016/j.jher.2017.08.002

[5] Louati, Moez, and Mohamed S. Ghidaoui. "Eigenfrequency shift mechanism due to variation in the cross sectional area of a conduit." Journal of Hydraulic Research 55, no. 6 (2017): 829-846. https://doi.org/10.1080/00221686.2017.1394373

[6] Wang, Xun, and Mohamed S. Ghidaoui. "Pipeline leak detection using the matched-field processing method." Journal of Hydraulic Engineering 144, no. 6 (2018): 04018030. https://doi.org/10.1061/(ASCE)HY.1943$\underline{7900.0001476}$

[7] Zhang, Chi, Jinzhe Gong, Aaron Zecchin, Martin Lambert, and Angus Simpson. "Faster inverse transient analysis with a head-based method of characteristics and a flexible computational grid for pipeline condition assessment." Journal of Hydraulic Engineering 144, no. 4 (2018): 04018007. https://doi.org/10.1061/(ASCE)HY.19437900.0001438

[8] Watters, Gary Z. "Modern analysis and control of unsteady flow in pipelines." Ann Arbor Science, United States (1980).

[9] Karney, Bryan W., and Duncan McInnis. "Efficient calculation of transient flow in simple pipe networks." Journal of Hydraulic Engineering 118, no. 7 (1992): 1014-1030. https://doi.org/10.1061/(ASCE)0733-9429(1992)118:7(1014)

[10] Afshar, M. H., and M. Rohani. "Water hammer simulation by implicit method of characteristic." International Journal of Pressure Vessels and Piping 85, no. 12 (2008): 851-859. https://doi.org/10.1016/j.ijpvp.2008.08.006 
[11] Chaudhry, M. Hanif. Applied Hydraulic Transients. Springer Science \& Business Media, 2014. https://doi.org/10.1007/978-1-4614-8538-4

[12] Wylie, E. B. "Frictional Effects in Unsteady Turbulent Pipe Flows." Applied Mechanics Reviews 50, no. 11S (1997): S241. https://doi.org/10.1115/1.3101843

[13] Zielke, W. "Frequency-Dependent Friction in Transient Pipe Flow." ASME, J. Basic Eng. 90 (1968): 109-115. https://doi.org/10.1115/1.3605049

[14] Pezzinga, Giuseppe. "Evaluation of unsteady flow resistances by quasi-2D or 1D models." Journal of Hydraulic Engineering 126, no. 10 (2000): 778-785. https://doi.org/10.1061/(ASCE)0733-9429(2000)126:10(778)

[15] Pezzinga, Giuseppe. "Local balance unsteady friction model." Journal of Hydraulic Engineering 135, no. 1 (2009): 45-56. https://doi.org/10.1061/(ASCE)0733-9429(2009)135:1(45)

[16] Brunone, Bruno, Marco Ferrante, and Francesco Calabresi. "Discussion of "Evaluation of unsteady flow Resistances by Quasi-2D or 1D models" by Giuseppe Pezzinga." Journal of Hydraulic Engineering 128, no. 6 (2002): 646-647. https://doi.org/10.1061/(ASCE)0733-9429(2002)128:6(646)

[17] Duan, Huan Feng, Mohamed S. Ghidaoui, and Yeou-Koung Tung. "An efficient quasi-2D simulation of waterhammer in complex pipe systems." Journal of Fluids Engineering 131, no. 8 (2009): 081105. https://doi.org/10.1115/1.3176978

[18] Brunone, Bruno, Bryan W. Karney, Michele Mecarelli, and Marco Ferrante. "Velocity profiles and unsteady pipe friction in transient flow." Journal of Water Resources Planning and Management 126, no. 4 (2000): $236-244$. https://doi.org/10.1061/(ASCE)0733-9496(2000)126:4(236)

[19] Soares, Alexandre Kepler, Dídia IC Covas, and Helena M. Ramos. "Damping analysis of hydraulic transients in pumprising main systems." Journal of Hydraulic Engineering 139, no. 2 (2013): $233-243$. https://doi.org/10.1061/(ASCE)HY.1943-7900.0000663

[20] Adamkowski, Adam, and Mariusz Lewandowski. "Experimental examination of unsteady friction models for transient pipe flow simulation." Journal of Fluids Engineering 128, no. 6 (2006): 1351-1363. https://doi.org/10.1115/1.2354521

[21] Nikpour, M. R., A. H. Nazemi, A. Hosseinzadeh Dalir, F. Shoja, and P. Varjavand. "Experimental and numerical simulation of water hammer." Arabian Journal for Science and Engineering 39, no. 4 (2014): 2669-2675. https://doi.org/10.1007/s13369-013-0942-1

[22] Duan, H. F., Silvia Meniconi, P. J. Lee, B. Brunone, and Mohamed Salah Ghidaoui. "Local and integral energy-based evaluation for the unsteady friction relevance in transient pipe flows." Journal of Hydraulic Engineering 143, no. 7 (2017): 04017015. https://doi.org/10.1061/(ASCE)HY.1943-7900.0001304

[23] Prashanth Reddy, H., Walter F. Silva-Araya, and M. Hanif Chaudhry. "Estimation of decay coefficients for unsteady friction for instantaneous, acceleration-based models." Journal of Hydraulic Engineering 138, no. 3 (2012): 260271. https://doi.org/10.1061/(ASCE)HY.1943-7900.0000508

[24] Holmboe, Ernest L., and Wilfred T. Rouleau. "The effect of viscous shear on transients in liquid lines." J. Basic Eng. 89, no. 1 (1967): 174-180. https://doi.org/10.1115/1.3609549

[25] Pezzinga, Giuseppe. "Local balance unsteady friction model." Journal of Hydraulic Engineering 135, no. 1 (2009): 45-56. https://doi.org/10.1061/(ASCE)0733-9429(2009)135:1(45)

[26] Szymkiewicz, Romuald, and Marek Mitosek. "Numerical aspects of improvement of the unsteady pipe flow equations." International Journal for Numerical Methods in Fluids 55, no. 11 (2007): 1039-1058. https://doi.org/10.1002/fld.1507

[27] Khamoushi, Alireza, Alireza Keramat, and Ali Majd. "One-Dimensional Simulation of Transient Flows in NonNewtonian Fluids." Journal of Pipeline Systems Engineering and Practice 11, no. 3 (2020): 04020019. https://doi.org/10.1061/(ASCE)PS.1949-1204.0000454

[28] Majd, Ali, Ahmad Ahmadi, and Alireza Keramat. "Investigation of non-Newtonian fluid effects during transient flows in a pipeline/Preiskava vplivov nenewtonske tekocine med prehodnimi tokovi v cevovodu." Strojniski VestnikJournal of Mechanical Engineering 62, no. 2 (2016): 105-117. https://doi.org/10.5545/sv-ime.2015.2787

[29] Wahba, E. M. "Runge-Kutta time-stepping schemes with TVD central differencing for the water hammer equations." International Journal for Numerical Methods in Fluids 52, no. 5 (2006): 571-590. https://doi.org/10.1002/fld.1188 